\title{
Tracing Echinococcosis in Portugal - The Role of the Abattoirs in North Douro Region
}

\author{
Machado $\mathrm{E}^{1}$, Conceição $\mathrm{MAP}^{\star 2}$, Castro $\mathrm{A}^{3}$, Costa $\mathrm{IMH}^{2}$, Gaspar $\mathrm{JJ}^{2,4}$, da Costa $\mathrm{RPR}^{2,4}$ and Costa JMJ ${ }^{3}$ \\ ${ }^{1}$ Directorate for Food and Veterinary Services of the North Region, Ministry of Agriculture, Forestry and Rural \\ Development, Portugal \\ ${ }^{2}$ Department of Animal Sciences, Polytechnic of Coimbra, Agriculture School, Bencanta, Coimbra, Portugal \\ ${ }^{3}$ Centre for Parasite Biology and Immunology, R\&D Unit, Department of Infectious Diseases, National Institute of \\ Health Dr. Ricardo Jorge, INSARJ, Porto, Portugal \\ ${ }^{4}$ CERNAS, Coimbra Agriculture School, Bencanta, Coimbra, Portugal
}

*Corresponding author: Conceição MAP, Department of Animal Sciences, Polytechnic of Coimbra, Agriculture School, Bencanta, 3045-601 Coimbra, Portugal, Fax: +351 23980 2979, Tel: +351 239802271 , E-mail: toinha@esac.pt

Citation: Machado E, Conceição MAP, Castro A, Costa IMH, Gaspar JJ, et al. (2017) Tracing Echinococcosis in Portugal - The Role of the Abattoirs in North Douro Region. J Vet Sci Ani Husb 6(1): 101. doi: 10.15744/23489790.6.101

Received Date: November 28, 2017 Accepted Date: February 26, 2018 Published Date: February 28, 2018

\begin{abstract}
The occurrence of cystic echinococcosis (CE) at a national level or in large regional areas is an issue difficult to determine in a costeffective way, integrating both human and animal data, and thus leading to effective control measures. In Portugal, the abattoirs in north Douro region receive a large percentage of heads of cattle from the whole country which makes them ideal places for the implementation of a surveillance system for this zoonosis. Data was obtained for cattle slaughtered in 9 abattoirs in north region of Douro River, with visible $C E$-like cysts at meat inspection. An excel database was constructed with the records of condemned viscera due to hydatid cysts in cattle for 2008, 2009, 2010, and the first half of 2011. Most of the cysts were found in the lungs and livers (23.5\%), only in livers $(21.5 \%)$ or only in lungs $(18.1 \%)$. Individual information concerning each animal contributed to the depiction of a distribution map by regions of the occurrence of positive cases in Portugal. From the 149 cases registered, it was possible to identify the place of infection in 93 cases (62.4\%), in which the rate of distribution was 21 (22.6\%) in the north, 14 (15.1\%) in the center, 57 (61.3\%) in Alentejo and 1 case (1.1\%) in Algarve. This distribution of cases coincides with the location of human and animal cases reported before, with special focus on the Alentejo and in the northeast of the country.
\end{abstract}

Keywords: Cystic echinococcosis; Passive surveillance; Abattoir; Cattle

\section{Introduction}

Cystic echinococcosis is an important zoonotic infection caused by the larval stages of taeniid cestodes of the genus Echinococcus with development in the viscera of the intermediate hosts. The adult tapeworm is found in the small intestine of the definitive host, which is the dog in the domestic cycle, from where segments containing eggs are passed with the faeces. After ingestion by the intermediate host, the larvae released from the eggs penetrate into the lymphatic or vascular system, reaching the liver, lungs or other internal organs to develop into hydatid cysts [1]. The size of cysts in the human organs is highly variable, usually ranging between 1 and $15 \mathrm{~cm}$, but much larger cysts may also occur. The same authors referred that it can take up to 10 months or longer after infection for the cysts to become visible in animal species. Whenever these affected viscera are being eaten by the dog, the life cycle is completed in about 4 to 5 weeks with the development of the protoscoleces into adult and mature Echinococcus in the small intestine of the definitive host [1]. Lungs and liver are the most affected organs in the intermediate hosts depending on the adaptation of Echinococcus strain to the host species [2].

So far as it is known, the occurrence of E. granulosus sensu stricto (ss) prevails in most regions of Portugal, either in sheep or in cattle [3]. Thus, E. granulosus which is important for human infection is endemic in the country [3-5].

Concerning intermediate host evaluation, the passive surveillance of infection, through the monitoring of livestock slaughtered in abattoirs is considered a reliable surveillance system, although unable to determine prevalence [6]. Cattle are recognized as the most important intermediate host involved in the transmission of CE in several parts of the world, mainly in the regions where 
cattle are predominant [7], such as in Brazil [8], in Tanzania [9], in Ethiopia [2,10], in Iran [11], in Pakistan [12] and in India [13]. There is a dearth of work in Portugal mainly in what concerns the cattle as an intermediate host of Echinococcus granulosus.

CE has a number of important economic effects, of which the most important is the cost of medical treatment for human cases and the decreased quality of life. The total cost of the disease in humans is the sum of costs for the health services and care [14,15]. Furthermore, the additional cost of loss of edible offal from farm animals due to the larval cysts is quite evident. This may result in direct costs such as the loss of the entire organ or, at least, the trimming and downgrading of that organ during inspection act, and indirect costs like its negative impacts on live weight gain, milk yield, fertility and carcasses value [15] estimated as $10 \%$ or more [14]. Moreover, costs of morbidity and losses in animal productivity in some countries where CE has a high prevalence can ascend to 2.2 billion USD annually $[5,14,16]$. The low sensitivity of the direct microscopy based on coprological techniques for the diagnosis of echinococcosis in dog [17-21], the non-reproducible coproantigen ELISA technics on a large scale [22] and the infeasibility of the diagnosis in farm animals [11], make the post-mortem routine examination at abattoirs the standard method for detecting CE in livestock [20].

Data obtained from cattle slaughtered in the abattoirs in north Douro region, with visible CE-like cysts at meat inspection, was used to map the cases of echinococcosis/hydatidosis, as had been previously suggested [23]. The objective of this study was to show the importance of the abattoirs of north Douro as a potential observatory for human and animal CE, in Portugal.

\section{Material and Methods}

\section{Abattoir data}

In this work, the methodology approach previously initiated was adopted [23]. The basic data for this study was gathered from the data registration program in use at the Official Veterinary Services of North Region for monitoring of the Compulsory Notification Diseases (CND) in the sixteen abattoirs of the region, named from A to P (Figure 1). The database included all the records from veterinary inspectors involved in the monitoring system of CND. In Portugal, during the period of study, 1,488,505 heads of cattle were slaughtered for consumption. The number of heads slaughtered during this period in these abattoirs was 449,442 in 2008 , 444,567 in 2009, 402,297 in 2010 and 192,199 in the first half of 2011. According to the official data and when compared to the total number of cattle slaughtered in continental Portugal, about $48 \%$ of the cattle were slaughtered in the abattoirs of the north in 2008 and 2009, and 37\% in 2010. Alentejo region is the buying point of weaned calves which are fattened and finished in center and north regions. This flow pattern with the slaughtering of cattle in the abattoirs of north Douro is typical and constant.

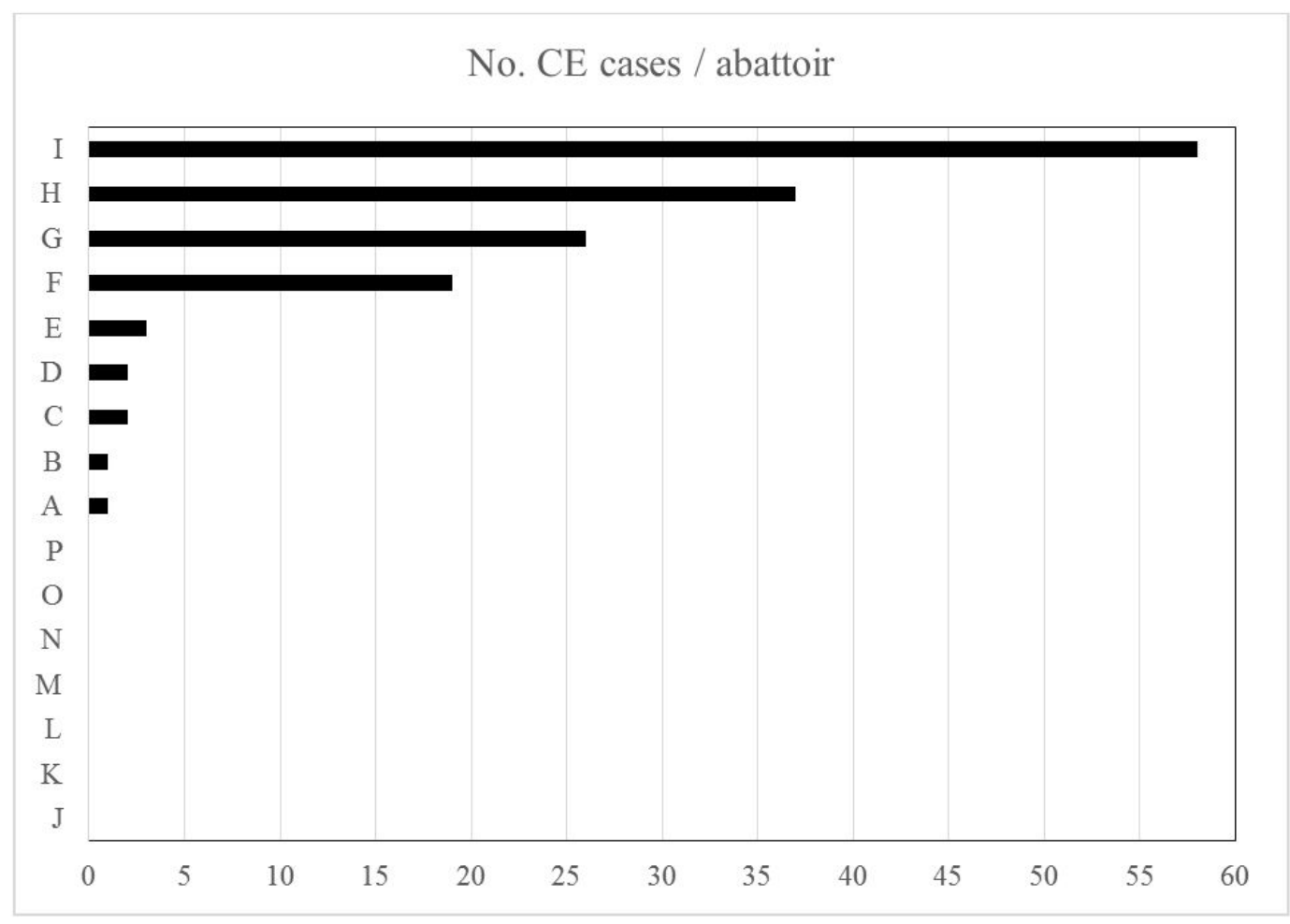

(A to $\mathrm{P}=$ abattoir label)

Figure 1: Number of CE cases reported per abattoir in north Douro region. The abattoirs P, O, N, M, L, K, J had no case report

Slaughtered cattle were examined for the presence of hydatid cysts in visceral organs including lungs, liver, heart, spleen and kidneys. Visual inspection and palpation followed by multiple incisions were carried out by the veterinary inspection team and the CE- like cysts were macroscopically confirmed. 
From the data collected, an excel database was constructed using the individual information of each animal that had visible CE-like cysts, such as slaughter date, slaughter house identification, breed, sex, age, ear tag number, date of birth, the official mark of the farms in which the animals were born or had passed through, including the number of months of stay and finally, the location of the cysts on the organ. The data report was obtained from nine of the sixteen abattoirs, in the north region (Figure 2).

\section{Map construction}

A map was constructed at a municipality level (NUT II) taking into consideration the number of cattle positive for CE that were labeled/identified in that municipality (Figure 2). The data allowed the tracing of the infected cattle in order to establish the farm location as a likely place of infection. Some assumptions were made to enable the processing of the collected data, first the reliability of the inspection act and the laboratory identification of the cysts. Second, it was assumed that one year is the minimum time period required for the development of a macroscopically visible cyst [24] that can be detected at post-mortem inspection. Third, whatever the time period between birth and slaughtering, if the animal remained in the same municipality it was considered for map construction. Fourth, if the animal moved between municipalities and if the time lapse between birth and slaughter was less than 1 year, the birth region was considered as the infection one.

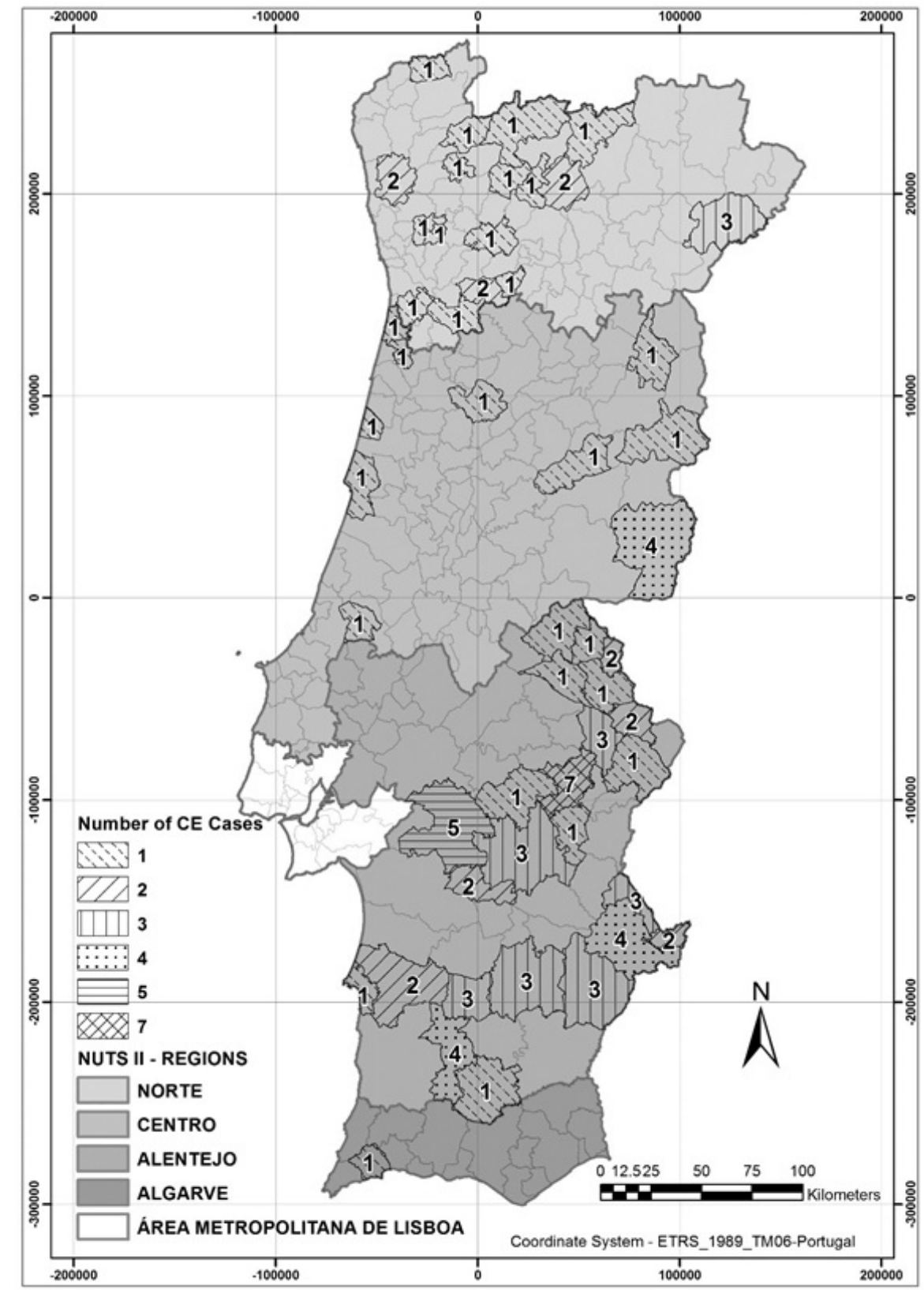

Figure 2: Mapping the distribution of the CE cases $(n=93)$ per municipality considering the place of infection, according to the adopted methodology

The map was produced using ArcGIS software, with the 2015 official Portuguese administrative boundaries data [25], using 
information of Municipalities, Districts and Regions. The database of cystic echinococcosis cases was then linked to the geographical data using the municipality's identification.

\section{Results}

Disparity of notification was huge (Figure 1). From the sixteen abattoirs (A to P), only nine of them (56.3\%) made the official notification of CE in cattle. Two abattoirs ( $\mathrm{H}$ and $\mathrm{I}$ ) reported $64 \%$ of all CE cases (37 and 59 cases respectively) and 2 of them (A and $\mathrm{B}$ ) reported only one case each (Figure 1).

Table 1 summarizes the location of the cysts in the organs. In a total of 149 infected animals, 51 of them (34.2\%) had no location registered, $32(21.5 \%)$ were located in the liver, 27 (18.1\%) in the lungs, 35 (23.5\%) in lungs and liver, 1 (0.7\%) in lungs, liver and heart, $2(1.3 \%)$ in lungs, liver, heart and kidney and $1(0.7 \%)$ in lungs, liver and kidney, showing in total, a slighter predominance of the liver location $(47.7 \%)$ and then in the lungs $(44.3 \%)$.

\begin{tabular}{|l|c|c|c|}
\hline \multicolumn{1}{|c|}{ Organ } & \multicolumn{2}{c|}{ Animals } \\
\hline & liver & No. & \% \\
\hline lung & 32 & 21.5 \\
\hline lung + liver & 27 & 18.1 \\
\hline lung + liver + heart & 35 & 23.5 \\
\hline lung + liver + heart + kidney & 1 & 0.7 \\
\hline lung + liver + kidney & 2 & 1.3 \\
\hline NR & 1 & 0.7 \\
\hline Total & 51 & 34.2 \\
\hline Liver + other locations & $\mathbf{1 4 9}$ & \\
\hline Lung+ other locations & $\mathbf{7 1}$ & 47.7 \\
\hline
\end{tabular}

$(\mathrm{NR}=$ non registered)

Table 1: Location of cysts in the organs of the 149 animals (number and percentage of animals)

From the data collected, it was noted that $96 \%$ of the 149 animals affected were females, $94 \%$ of them were more than 5 years and that the rate of CE increased with age (Table 2), showing that only $6.0 \%$ were between $0-5$ years, $20.1 \%$ between $5-10$ years of age, and $73.8 \%$ were over 10 years old. Further, the cross breed showed a higher occurrence of cysts, with $60.4 \%$ of the cases, followed by the selected breeds (Frisian, Charlois, Limousin) with 15.4\%, then autochthonous breeds (Alentejana, Arouquesa, Barrosã, Marinhoa, Maronesa, Mertolenga and Minhota) with $14.8 \%$ and $9.4 \%$ for undetermined breeds.

\begin{tabular}{|c|c|c|}
\hline & \multicolumn{2}{|c|}{ Animals } \\
\hline Age classes (years) & No. & $\%$ \\
\hline $\mathbf{0 - 5}$ & 9 & 6.0 \\
\hline $\mathbf{5 . 1 - 1 0}$ & 30 & 20.1 \\
\hline$>\mathbf{1 0}$ & 110 & 73.9 \\
\hline Total & $\mathbf{1 4 9}$ & \\
\hline
\end{tabular}

Table 2: Distribution of CE cattle cases by age classes (number and percentage of animals)

After data processing and according to our methodology, it was possible to establish the region of infection for 93 cases. In the remaining 56 cases it was not possible to determine the place of infection due to the degree of itinerancy of the animals, moving from one farm to another, usually for short periods. Of all the cattle registered with CE, about 50\% had moved farms two to three times. Taking into consideration the number of CE per municipality (Figure 2) and as per regions (Table 3) it was possible to obtain information for the whole country. The distribution of the 93 cases is as follows: $21(22.6 \%)$ animals in the northern region (Norte), $14(15.1 \%)$ cases in the central region (Centro), and in the southern region, 57 (61.3\%) from Alentejo and 1 (1.1\%) from Algarve.

\begin{tabular}{|c|c|c|}
\hline & \multicolumn{2}{|c|}{ Traced animals } \\
\hline Region & No. & \% \\
\hline North & 21 & 22.6 \\
\hline Center & 14 & 15.1 \\
\hline Alentejo & 57 & 61.3 \\
\hline Algarve & 1 & 1.0 \\
\hline & $\mathbf{9 3}$ & \\
\hline
\end{tabular}

Table 3: Distribution of 93 CE cases by large regions of Portugal, traced according to the referred methodology of data processing (number and percentage of the 93 traced cases) 


\section{Discussion}

Itinerancy of cattle is a risk practice with consequences for animal health, but is recognized in Portugal as a fact, leading to a constant flow of cattle from different parts of the country to be slaughtered in the abattoirs of north Douro region. Additionally, it is the older animals that are slaughtered there, as confirmed by this study. Females represent $96 \%$ of the cases since they are from dairy farms and males are from meat production units, thus slaughtered younger. In the youngest animals the cysts have not enough time to become visible at inspection. Even so, after consulting the available data, it was possible to identify the place of infection of $62.4 \%$ of the animals and to map the distribution of the CE cases at a national level. There is an evidence of overlay of the regions presented in this study and those that were previously recognized as having a higher risk for echinococcosis in humans and sheep [26,27], which also coincides with extensive farming systems in Alentejo, the major cattle producing region of the country [28], which is in continuity with the western region of Spain, where echinococcosis/hydatidosis is considered an endemic and re-emergent zoonosis [29]. A similar successful observatory system has been reported in other parts of the world, like in USA for Notifiable diseases [30], in southwestern Nigeria for brucellosis [31] and in Tanzania for zoonotic diseases in cattle [32], among many others. In Portugal, whatever may be the prevalence of echinococcosis/hydatidosis, the proposed methodology would remain cost-effective when compared to active surveillance [6]. However, misclassification errors have been shown to occur when macroscopic diagnosis is used alone without confirmation by histology [24,33] or through molecular methods. The previous study in the same abattoirs as presented in this study and with the same veterinary team revealed, after laboratory confirmation, a margin of error of 3.39\% for CE identification [23]. False positives due to other cyst-like lesions or other Taniidae species and false negatives due to small developing cysts must also be considered, especially in the liver, as it is an organ with commercial interest and, as a result, where the inspections incisions are minimized. This methodology is quite acceptable considering that echinococcosis/hydatidosis is a chronic and non-specific symptoms disease [34]. Unfortunately, the CE fertility and molecular studies were not accomplished which compromises the understanding of the role of cattle and their contribution to the epidemiology of Echinococcus granulosus ss in Portugal, although its presence is confirmed in this animal species [3], in the inland region. In general, cattle have been considered as a poor host for this cluster, although some studies have demonstrated that cattle may play a role as a reservoir in some regions around the world, constituting a risk for human health $[4,7,8,11]$. Disparity of notification of CE cases reveals a lack of participation and commitment of some inspection teams in this study. In Portugal, considering the national representativeness of the abattoirs of north Douro for cattle, and taking into consideration these CE findings, measures should be promoted, namely the National Compulsory Notification system should be accomplished at veterinary and human health services, the participation of a properly qualified laboratory for evaluation of CE cysts fertility and genotyping and the promotion of the training and motivation of the inspection team at the abattoirs.

\section{Acknowledgements}

This work received financial support from National Funds (FCT/MEC, Fundação para a Ciência e Tecnologia and Ministério da Educação e Ciência) under the Partnership Agreement UID/MULTI/00211/2013. We thank the veterinary inspection teams of the abattoirs and all those who contributed to make this work possible.

\section{References}

1. Eckert J, Deplazes P (2004) Biological, Epidemiological and Clinical Aspects of Echinococcosis, a Zoonosis of Increasing Concern. Clin Microbiol Rev 17: 107-35. 2. Negash K, Beyenea D, Kumsa B (2013) Cystic echinococcosis in cattle slaughtered at shashemanne municipal abattoir, south central Oromia, Ethiopia: Prevalence, cyst distribution and fertility. Trans R Soc Trop Med Hyg 107: 229-34.

3. Beato S, Parreira R, Calado M, Grácio MAA (2010) Apparent dominance of the G1-G3 genetic cluster of Echinococcus granulosus strains in the central inland region of Portugal. Parasitol Int 59: 638-42.

4. Romig T, Ebi D, Wassermann M (2015) Taxonomy and molecular epidemiology of Echinococcus granulosus sensu lato.Vet Parasitol 213: 76-84.

5. Dakkak A (2010) Echinococcosis/hydatidosis: A severe threat in Mediterranean countries. Vet Parasitol 174: 2-11.

6. Hadorn DC, Stark KD (2008) Evaluation and optimization of surveillance systems for rare and emerging infectious diseases. Vet Res 39: 57.

7. Andresiuk MV, Gordo FP, Bandera CC, Elissondo MC, Dopchizi M, et al. (2009) Echinococcus granulosus : biological comparison of cattle isolates from endemic regions of Argentina and Spain. Rev Argent Microbiol 41: 218-25.

8. de La Rue ML (2008) Cystic echinococcosis in southern Brazil. Rev Inst Med Trop Sao Paulo 50: 53-6.

9. Stroup S, Tongjai S, Swai N, Maro A, Kibiki G, et al. (2012) Dual probe DNA capture for sensitive real-time PCR detection of Cryptosporidium and Giardia. Mol Cell Probes 26: 104-6.

10. Abebe A, Beyene D, Kumsa B (2014) Cystic echinococcosis in cattle slaughtered at Gondar Elfora export Abattoir, northwest Ethiopia. J Parasit Dis 38: 404-9.

11. Cardona GA, Carmena D (2013) A review of the global prevalence, molecular epidemiology and economics of cystic echinococcosis in production animals. Vet Parasitol 192: 10-32.

12. Latif AA, Tanveer A, Maqbool A, Siddiqi N, Kyaw-Tanner M, et al. (2010) Morphological and molecular characterisation of Echinococcus granulosus in livestock and humans in Punjab, Pakistan. Vet Parasitol 170: 44-9.

13. Singh BB, Sharma JK, Ghatak S, Sharma R, Bal MS, et al. (2012) Molecular epidemiology of Echinococcosis from food producing animals in north India. Vet Parasitol 186: 503-6.

14. Torgerson PR (2003) Economic effects of echinococcosis. Acta Trop 85: 113-8.

15. Benner C, Carabin H, Sánchez-Serrano LP, Budke M, Carmena D (2010) Analysis of the economic impact of cystic echinococcosis in Spain. Bull World Health Organ 88: 49-57. 
16. Getaw A, Beyene D, Ayana D, Megersa B, Abunna F (2010) Hydatidosis: Prevalence and its economic importance in ruminants slaughtered at Adama municipal abattoir, Central Oromia, Ethiopia. Acta Trop 113: 221-5.

17. Deplazes P, Eckert J (2001) Veterinary aspects of alveolar echinococcosis - a zoonosis of public health significance. Vet Parasitol 98 : $65-87$.

18. Contesse P, Hegglin D, Gloor S, Bontadina F, Deplazes P (2004) The diet of urban foxes (Vulpes vulpes) and the availability of anthropogenic food in the city of Zurich, Switzerland. Mamm Biol 69: 81-95.

19. Cardoso AS, Costa IMH, Figueiredo C, Castro A, Conceição MAP (2014) The occurrence of zoonotic parasites in rural dog populations from northern Portugal. J Helminthol 88: 203-9.

20. Carmena D, Cardona GA (2014) Echinococcosis in wild carnivorous species: Epidemiology, genotypic diversity, and implications for veterinary public health. Vet Parasitol 202: 69-94.

21. Mateus TL, Castro A, Ribeiro JN, Vieira-Pinto M (2014) Multiple Zoonotic Parasites Identified in Dog Feces Collected in Ponte de Lima, Portugal - A Potential Threat to Human Health. Int J Environ Res Public Health 11: 9050-67.

22. Deplazes P, Van Knapen F, Overgaauw PA, Schweiger A (2015) Role of pet dogs and cats in the transmission of helminthic zoönoses in Europe, with a focus on echinococcosis and toxocarosis. Vet Parasitol 182: 41-53.

23. Duarte L, Afonso A, Capêlo V (2006) Resultados de um "programa sentinela” de vigilância da hidatidose em bovinos, em unidades de abate no EDM. RPCV, VI Enc Soc Port Epid Med Vet Prev 101: 319-41.

24. Eckert J, Gemmell MA, Meslin F-X, Pawłowski ZS (2001) WHO / OIE Manual on Echinococcosis in Humans and Animals: a Public Health Problem of Global Concern Edited Paris: World Organisation for Animal Health, Switzerland.

25. Directorate-General of the Territory (2017) Online Maps Service, Portugal.

26. De Morais D (1998) A Hidatologia em Portugal, Fundação Calouste Gulbenkian Lisboa, Portugal.

27. Morais JAD (2007) Hidatidose humana Estudo Clínico-Epidemiológico no Distrito de Évora Durante um Quarto de Século. Acta Médica Port 20: 1-10.

28. Instituto Nacional de Estatística (2016) Inquérito aos efectivos animais. Efectivo bovino por Localização geográfica e Categoria, Portugal.

29. Rojo-Vazquez FA, Pardo-Lledias J, Francos-Von Hunefeld M, Cordero-Sanchez M, Alamo-Sanz R, et al. (2011) Cystic Echinococcosis in Spain : Current Situation and Relevance for Other Endemic Areas in Europe. PLoS Negl Trop Dis 5: e893.

30. Van Klink AGM, Prestmo PG, Grit A (2015) Animal health and disease monitoring in the abattoir. Livestock 20: $330-5$.

31. Joseph OA, Oluwatoyin AV, Comfort AM, Judy S, Babalola CSI (2015) Risk factors associated with brucellosis among slaughtered cattle: Epidemiological insight from two metropolitan abattoirs in Southwestern Nigeria. Asian Pacific J Trop Dis 5: 747-53.

32. Swai ES, Schoonman L (2012) A survey of zoonotic diseases in trade cattle slaughtered at Tanga city abattoir: A cause of public health concern. Asian Pac J Trop Biomed 2: 55-60.

33. Craig P, Mastin A, van Kesteren F, Boufana B (2015) Echinococcus granulosus: Epidemiology and state-of-the-art of diagnostics in animals. Vet Parasitol 213: 132-48.

34. FAO (2014) Risk-based disease surveillance - A manual for veterinarians on the design and analysis of surveillance for demonstration of freedom from disease. FAO Animal Production and Health Manual No. 17. Rome, Italy.

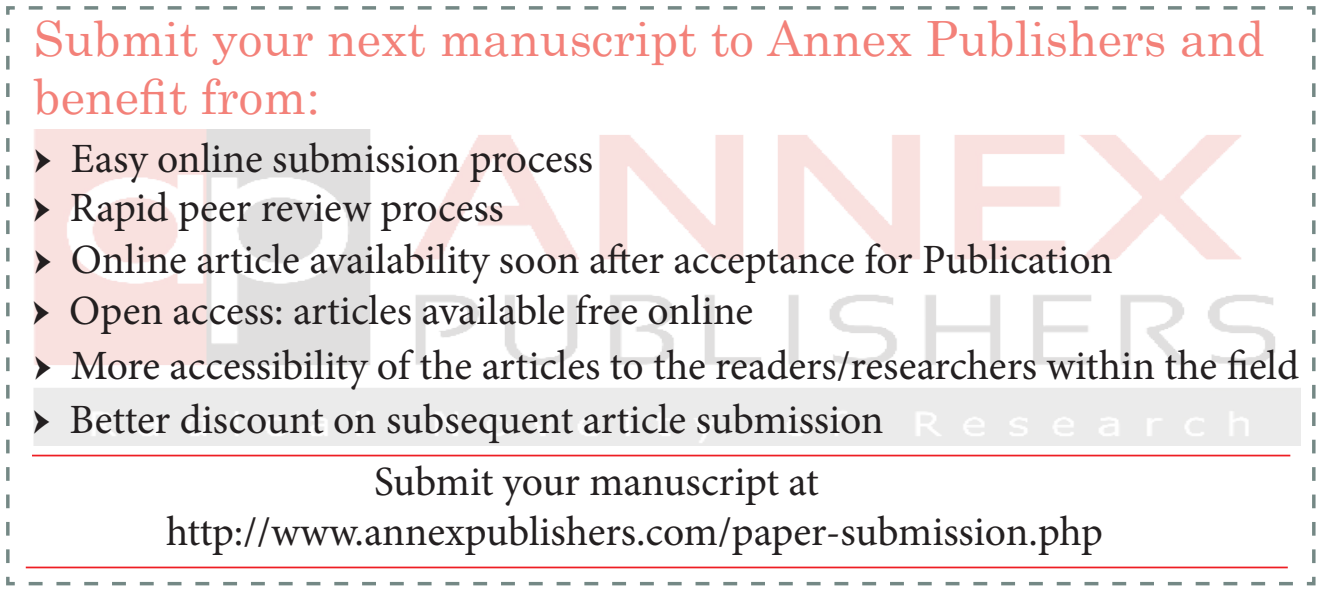

